\title{
Metamemories of Schooling: An Autoethnographic Inquiry
}

\author{
James A. Bernauer \\ Robert Morris University, Pennsylvania, USA
}

\begin{abstract}
An interview among three family members had been previously conducted among three family members in order to discuss perceptions of caring in $K-12$ through college and the continuing impacts of these perceptions on motivation to learn (see Bernauer [2]. The question then arose as to whether the memories and interpretations of the original events as reported may have been recast and transformed as a result of subsequent experience and reflection that were brought to mind as a result of both auto-ethnogrpahic writing and the interview itself. It was found that such a transformation seemed to have occurred both metacognitively and metaemotionally. We have termed these transformed memories as metamemories and are conceptualized as part of individuals' ongoing efforts to re-construct and integrate knowledge, experience, and insights and a coherent world view. This study was conducted within the framework of Piagetian and Constructivist Learning Theory, Polanyi's propositional and tacit knowledge, and more recent research on nostalgia. It is hoped that readers will find value in this inquiry for understanding the relation between caring and motivation to learn as well as how memories of caring and non-caring continue to be transformed and re-interpreted as a function of both time and later experiences.
\end{abstract}

\section{Introduction}

"Isn't it amazing the way the future succeeds in creating an appropriate past". John Leonard

"If you talk to my sister and me you would think we have different parents and grew up in different houses. What is actually different is that we are very different people so everything we experienced we perceived differently and therefore remember things differently." (personal communication from "KC" a doctoral student)

The above quotes get at the heart of the matter regarding memories since, while we may forget details of past events, we never quite forget how each of us thought or felt about them especially if they are related to our deepest-held beliefs and emotions. This study focused on memories of caring in schooling builds on this understanding by positing that, as a consequence of both metacognition (thinking about our thinking, feelings, and experiences past, present, and anticipated future) and metaemotion (feeling about our thinking, feelings, and experiences past, present, and anticipated future), we further transform our perceptions and interpretations of our memories beyond their initial perceptions and interpretations as we reflect upon them cognitively and as we experience them again emotionally. These transformed memories are referred to as metamemories.

The purpose of this study was to investigate whether the perceptions and interpretations of memories of these family members related to caring in schooling may have been transformed or recast as a result of subsequent experience and reflection. This study might be thought of as a sequel to a prior study where three participant family researchers discussed their memories of caring and non-caring shown by teachers [2]. However, this current study investigates possible transformations of these memories as a consequence of ongoing metacognitive and metaemotional processes. These metamemories are conceptualized as part of our ongoing efforts to integrate and reconstruct our experiences in order to maintain a coherent world view. Letters-to-Self were used as the primary method of data collection where each participant responded to prompts that were designed to elicit reflections about their memories and to discover to what extent these memories may have been transformed into metamemories. In this sense, this study is autoethnographic since Letters-toSelf allowed each participant to explore multiple layers of consciousness and the vulnerability of self [22]. This study might also be viewed as retrospective-longitudinal because it investigates a different aspect of the prior study [2]; that is, while this current study is removed from the original one in time, it is also connected to it because it has a different purpose and seeks to further explore different phenomena. The research questions are:

i. To what extent have perceptions and interpretations of memories of family members been transformed or recast as a result of subsequent experience and reflection?

ii. Are memory transformations shaped by all past experiences or do we pick and choose those experiences that matter? 


\section{Paradigms, Ethnography and Autoethnography}

Kuhn [17] noted that there were ongoing disagreements among social scientists regarding the "nature of legitimate scientific problems and methods" but added that, while there was a lack of controversy among natural scientists regarding problems and methods, that that he doubted that they possess a better understanding about these phenomena than social scientists. As a consequence of these differences, Kuhn coined the term paradigm to connote the differences among communities of practitioners regarding those scientific achievements they view as "model problems and solutions". While these differences have sometimes been referred to as the "paradigm wars" where one side believes that the quantitative paradigm offers the most credible way to pursue scholarly inquiry while the other side views the qualitative paradigm as the exemplar for identifying model problems and solutions [7]. However, Guba [10] points out that the term paradigm itself suffers from a clear accepted definition among scholars and proposes that we simply define it as "a basic set of beliefs that guides action". It is because of this simplified and understandable definition that practitioners are then able to enter into dialogue about the legitimacy of different approaches for pursuing scholarly inquiry.

When trying to determine what research approach to use to investigate the research questions in this study, it became apparent that because "perceptions and interpretations" were of central concern, that the naturalistic or qualitative paradigm rather than the quantitative or rationalistic paradigm matched best to this study. The rationale for this choice is that the assumptions underlying the naturalistic paradigm recognize the existence of multiple realities and that context is a central part of truth statements. In contrast, the rationalistic or quantitative paradigm posits that there is a single reality that can be partitioned into discrete variables and that enduring context-free truth statements can be generalized to other settings provided that an adequate number of participants or objects have been randomly selected and included in the study. However, I agree wholeheartedly with those who say that if viewed a wide enough yet deep enough perspective, that rather than being antagonistic, that these paradigms can actually be complementary for understanding phenomena [9], [13], [24]. This perspective has led scholars to investigate and use "mixed methods" in scholarly inquiry especially in the social sciences [3], [4], [12]. However, for this study, I have chosen to stay within the realm of qualitative inquiry because the topic does not seem to require "mixing" methods in order to achieve its aims but rather requires an investigation of deeply held feelings, perceptions, and beliefs in relation to how memories of past events become transformed.

While the qualitative paradigm is more akin to the aims of this study, there are various approaches or designs under this paradigm where five of the most notable include Narrative, Phenomenological, Grounded Theory, Ethnographic, and Case Study [5]. And so, the next decision was which of these approaches to use. Just as in mixing methods across the qualitative and quantitative paradigms, we can also do so within paradigms. For example, Creswell and Poth [5] describe "turning the story" in order to investigate a phenomenon of interest using any of these five approaches. While it is not the purpose of this current study to explicate what each of these five approaches entail, suffice it to say that, while they use unique approaches for collecting and analyzing data, that they all share a common interest in how individuals perceive and interpret phenomena and thus construct their own understandings of these phenomena. The term "construct" is pivotal since the qualitative paradigm has clear connections to Constructivist Learning Theory (for example, see Lincoln and Guba [20]).

Ethnographic approaches are designed to investigate cultures and the social interactions within these cultures and is related to the field of anthropology while psychology is the study of individuals, sociology is the study of groups, and archeology is the study of objects [19]. This fragmentation into disciplines, while necessary in order to focus our inquiries, should not be allowed to obscure the gestalt of those complexities that define us as human beings including our own reflections about our past, present, and futures - both who we are and who we are becoming. Enter autoethnography [11] building on the earlier work of others that offers us a way to self-narrate our lives from the vantage point of time and experience. Wolcott [33] cautions us however by saying (perhaps tongue in cheek) "but the term autoethnography exudes a certain self-explanatory air about it--one really ought to be able to figure out what it means". He then goes on to address this charge by stating that autoethnography has “ ...become a reporting style dealing with the lived experience of researchers themselves". And, it is indeed this kind of lived experience unearthed through autoethnography that was ultimately chosen to explore metamemories of schooling.

While autoethnography is the approach used in this study, it required that appropriate instruments be used to collect data. In this regard, "Letters-to-Self" [22] were used in order to further investigate the thoughts and emotions of participants. Tierney [29] wrote that "autoethnography confronts dominant forms of representation and power in an attempt to reclaim, through self-reflective response, representational spaces that have marginalized those 
of us at the borders". Specifically, for this current study, this methodology was used to investigate the feelings that were evoked when instances of caring and non-caring in schooling were discussed during an initial interview conducted in 2016. These letters could be thought of as a type of journaling where the individual seeks to forge a closer connection between tacit and propositional knowledge [27], [28]. These letters also serve as "rearview mirrors" where we can look retrospectively and reflectively at our experiences in a deeper and more personal manner since we are writing to ourselves rather than to an imagined audience. The letters generated the data in this study for understanding more clearly the tacit learning that may have occurred as thoughts and feelings were resurrected regarding remembered instances of caring and non-caring. Son-Researcher (SR) was the first researcher to write his letter based on his memories, thoughts, and feelings and then Mother-Researcher (MR) and Father-Researcher (FR) read and reflected on this letter and then wrote their own letters in response to SR.

\section{Conceptual Underpinnings of Metamemories}

Various perspectives were used in this study to construct a framework to facilitate a fuller understanding of findings. These perspectives are those offered by Piagetian Learning Theory [25] that includes the concepts of assimilation, accommodation, and equilibrium; Propositional versus Tacit Knowledge [27], [14], [4]; Constructivist Learning Theory which is a type of cognitive learning theory that posits that all new learning must be "re-constructed" in order to be understood by the learner [14], [20], [31]. This study attempted to "populate" this framework with the thoughts, feelings, insights, and apprehensions that arose as a consequence of re-exploring memories of instances of caring and non-caring by teachers of SR that took place during school years 2005 -2015 that comprised elementary school, high school, and college. I recognize that we are caught in somewhat of a paradox because while tacit knowledge "cannot be easily formalized and put into exact words" - The Tacit Dimension, Polanyi [28], that this is precisely what I am trying to do. As Berliner [1] observes "in fact, no unpoetic description of the human condition can ever be complete". While I agree that other expressive formats such as novels, music, art, film, drama, and poetry might more comfortably lend themselves to expressing the difficult-to-express, I have tried in this article to facilitate understanding of how our memories can be transformed as a result of ongoing metacognitive and metaemotional processes that occur over time.

It will come as no surprise to those who have published that what lay in front of you is not only the result of deliberate planning but also of unplanned doses of reflection, insights, collaboration, and serendipity. For example, while the article that you are now reading hopefully conforms to the accepted rules of grammar and style, the behind-the-scenes activities that preceded its publication are actually quite astounding. In fact, while any article or book must of necessity be written in an organized way using propositional language so readers can understand what lies in front of them, the processes that have led to this organized presentation are anything but linear and, if truth be told, a graphic representation of these processes along the dimension of time might be so iterative, reciprocal, overlapping, and complex as to render these processes unintelligible! These complexities include not only the visible interactions among participant researchers but also the invisible metacognitive and metaemotional processes that were simultaneously occurring within and among participant-researchers as this study was being conducted. The term metaemotional is emphasized here because, while readers are generally familiar with metacognition, the term metaemotional (as far as I know) has not previously been coined. As defined in the Definition of Terms, it is described here as feeling about our thinking, feelings, and experiences past, present, and anticipated future.

If we agree with Wolcott [32] that research is not complete until it has been written-up, it is indeed a formidable task we face when trying to transform these visible and invisible processes into an account using written language. When trying to make sense of empirical data and observational experiences, we need to "frame" findings in some way in order to make sense of them. I have found that in trying to do so in relation to metamemories, I needed to draw on Piagetian cognitive learning theory, constructivist learning theory as developed by several prominent theorists, and the application of propositional knowledge that can be communicated in language form that is associated more with an etic perspective. However, this study would be incomplete if there was also not a deep awareness of tacit knowledge as described by Michael Polanyi which is knowledge arising from intuition, insights, feelings, and other ways that cannot easily be communicated in language form but rather through art, drama, film, music, poetry, and silent speech and that is associated more with an emic perspective. (attributed to Michael Polanyi, [27]; [28]). It is hoped that perhaps through empathetic reading that readers themselves experience this latter type of knowledge.

\subsection{Piagetian Learning Theory}

Jean Piaget focused on how individuals develop cognitively from infancy to adulthood via stage theory [25], [26]. Although there have been 
criticisms of this theory because it underestimates the capacity of children at particular ages, his work is still considered quite useful for understanding cognitive development. Piaget's theory is especially poignant in relation to individuals' quest for stability or equilibrium as they are confronted with the forces of continuous environmental, social, and personal influences. Piaget posited that we use both assimilation and accommodation to achieve our need for equilibrium where assimilation helps us to incorporate new learning and understanding into our existing cognitive structures while accommodation is used to help us modify our existing cognitive structures in light of compelling new experiences and understanding. While Piaget viewed our search for equilibrium as primarily a cognitive process, these same components seem just as important in relation to metacognition, metaemotion, and metamemories. When we "think about our own thinking" (metacognition) are we not trying to come to grips with our thinking in such a way as to achieve harmony and balance? Similarly, when we find ourselves in some type of emotional turmoil or disturbance, don't we seek ways to sooth our emotions through exercise, music, walks along the beach, etc.? At the same time, lest we think of new experiences and understandings as unwanted assaults on our current thinking and feeling, we need to recognize that without the intrusion of thoughts and feelings that disturb us in some way, we cannot grow in understanding and appreciation of people, places, and things - this is where Piaget's concept of accommodation comes into play.

As a consequence of inciting new understandings to arise from our group interview and Letters-to-Self, we sought (perhaps unconsciously) to arrive at a new equilibrium in relation to our thoughts, feelings, and perspectives as memories were resurrected and tossed about both cognitively and emotionally. For this current study, it is conjectured that consistent with Piaget's theory, that all three participants have experienced some degree of assimilation and accommodation (even if we were unaware of these processes) as memories were transformed into metamemories via both metacognition and metaemotions. This conjecture is, of course, only a hypothesis and would require replication and endorsement from others before this whole sequence of constructs could be considered credible. However, I use it here as one of the components of a framework to help understand the concept of metamemories in relation to caring in education.

\subsection{Constructivist Learning Theory}

Constructivism recognizes that that our personal and social investment in learning is indispensable if we are to make such learning "our own" rather than learning that evaporates after a test is completed. In a sense, we all need to "reinvent the wheel" (contrary to traditional wisdom) in order to make our insights and new learning meaningful. Constructivist learning theory draws on the work of many scholars including Bruner, Dewey, Piaget, and Vygotsky [34] and can be thought of as being comprised of two strands individual and social. While the individual strand refers to new knowledge acquired through active thinking and reflecting by the individual, the social strand refers to the creation of new knowledge acquired through social interactions. Of course, the boundary between these two types of learning is both permeable and flexible - where one ends and the other begins is sometimes difficult to identify. However, the essential point is that as we go about living, we also go about learning in ways that are authentic to our own way of constructing new knowledge.

Kelly developed his theory of constructivism within the context of personality development. His "theory of personality and psychology of personal constructs" [14] offers us a potentially fruitful way to think about the connections between cognition and emotion. He writes that individuals look at the world "through transparent patterns or templates that he creates and then attempts to fit over the realities of which the world is composed" and he refers to these patterns as "constructs". He also makes the point that sometimes the fit between an individual's patterns and reality is not always accurate which takes us back to Piaget's concepts of assimilation, accommodation and equilibrium although Kelly's focus is on the "whole person" rather than man as thinker. This more integrated role of constructivism is what we see happening when we recall and reconstruct our memories.

\subsection{Polanyi's Tacit and Propositional Knowledge}

In addition to Piagetian ideas of cognitive growth and constructivist learning theory, the theoretical framework surrounding metamemories can also be seen to include the difference between propositional and tacit knowledge as identified by Michael Polanyi. While Piaget was concerned with the cognitive domain as formalized in terms of "stages", [27], [28] helps us recognize that what we know and understand exceeds what we can communicate. Emotions including feelings, intuition, insights, and apprehensions (tacit knowledge) are important components of our knowledge and understanding and are not easily expressed in language form (propositional knowledge). These ideas have also been treated by others such as Erikson [6] whose "Eight Ages of Man" (later identified as "Eight Stages of Psychosocial Development") looked at the needs of individuals as they grow and develop along 
an emotional dimension as well as the cognitive dimension.

It can be argued that we go about living our life based more on tacit knowledge rather than on the more formalized propositional knowledge that can be communicated via written and oral language. This is where the classic dichotomy of thinking versus feeling comes into play and where we might hear others or even ourselves say when we are being thinkers rather than feelers something like "you can't reason with (Dick or Jane) because they have let their feelings get the better of them". And it is indeed true that we sometimes can become blinded by our own emotions when we allow feelings to rule the roost. For example, under conditions where we, or our loved ones are in danger, we automatically revert to fight or flight. However, thinking about emotions and cognition in terms of either-or fails to recognize that there is a continual interplay of thought and emotion (in all its manifestations) as we go about discovering new knowledge about ourselves and the world.

The attainment of formal operational thinking (Piaget's highest stage of cognitive development) that enables an individual to consider multiple perspectives and engage in hypothetico-deductive reasoning, underlies metacognitive ability. However, if we recognize that tacit knowledge is a real and important component of human growth and development, then this non-cognitive aspect of our lives (for example: feelings, emotions, premonitions, intuitions) should be also integrated into our understanding of how memories can be transformed. That is, it is not only metacognition but also metaemotion that is at work when we revisit our past experiences including, as in the present case, memories of caring and non-caring as it relates to schooling.

\subsection{Nostalgia Research}

The nostalgia is another concept that relates to metamemories. However, the concept of nostalgia is most visibly seen in consumer marketing and advertising [15]. However, rather than view it as only a way to see products, recent research being conducted at the University of Southampton and the University of Surrey among others reveals that it offers us yet another window for understanding how memories can be used to create and perhaps to recreate ourselves [23]. Muller [21] has explored how the concept of ubuntu is intertwined with both the concepts of nostalgia and imagination where ubuntu is an African term that encompasses feelings related to kindness, fellowship, empathy, dreams, philosophy, and theology. Indeed, I found that nostalgia has played an important role for helping to understand how metamemories come about and hence how they help us to continuously re-construct who we are.

\section{Context and Findings}

Letters-to-self were used as the data collection method for this study which might be thought of as self-interviews and as such, data are not simply transmitted as ready-made products but rather are modified during the process of writing as a consequence of reflection and ongoing learning. Therefore, it was thought that these data could be better understood within the context of Piagetian learning theory, constructivist learning theory, and reference to the roles of tacit and propositional knowledge. I began my own letter- to- self in May, 2017 and concluded it in December, 2017. This letter was based on the letter written by our son (SR) who reflected on how his memories of instances of caring and non-caring by teachers in high school were redefined and interpreted. My wife (MR) also wrote a letter-to-self in which she too thought about how the interpretation of her memories may have been transformed. I harken back to our family interview conducted during the summer of 2016 when SR described his memories of caring and non-caring from elementary school through his current college years. Because SR lived at home during elementary school and high school, I already knew about most (not all) of the instances that he described during these years. However, it was during the group interview that I first heard SR describe these instances from his own perspective as a college student.

Regarding elementary school, I vividly recall SR's memory of his fourth-grade teacher (Ms. Wiley) because both MR and I had a meeting with the Principal and Ms. Wiley. As parents, we are all prone to defend our children from those that would hurt them and so as co-researchers we had to remind ourselves to be aware of this tendency whenever we evaluated situations such as this so that credibility would not be unduly damaged -- although I am pretty sure that we cannot completely eradicate parental bias! I do remember that Ms. Wiley seemed to be "burned out" after many years of teaching and especially teaching 10 - 11 year old boys. During this meeting, this teacher was not only less than cordial but was still adamant regarding an incident where she believed that SR intentionally tried to trip her in the classroom. SR had told us that he simply was sitting there with his leg out in the aisle somewhat (since he was tall even at that age) when she came from behind and hit his foot. Knowing our son as we do, it would have been very much out of character for him to try and hurt anybody, especially a teacher. In any event, the memory of sitting at this meeting with MR and me on one side of a desk and the Principal and Ms. Wiley on the other side will 
probably forever be one of my "flashbulb memories". This situation was eventually resolved, or more likely, just faded in importance due to the ongoing rapid pace of change that accompanies these early years. However, Ms. Wiley did retire at the end of SR's fourth grade year - I have always wondered if this incident contributed to her decision. I also find it comforting that even though SR discussed the impact that this teacher had on him in our previous study [2] that he did not mention this teacher as part of this current study - it may be the case that this memory has been transformed and incorporated into the ongoing process of constructing metamemories. SR also described "Mr. B." (pseudonym) during the interview who was a teacher in eighth grade as "probably the most effective teacher he ever had" because of the way he interacted with students and the respect that he showed them.

Mr. B was my 8th grade homeroom and science teacher. He was the first teacher to communicate with upper-elementary students beyond the syllabus and into our lives. Taking the jump from 7th to 8th grade, there was a notable advancement in the way we were spoken to. At the ripe old age of 13, two things improved in the classroom: personal disclosure and responsibility. Although we still were offered guidance in situations when we asked for help from $\mathrm{Mr}$. B, a lot of the responsibility to solve problems for ourselves and find the information on our own was also emphasized.

As I read this quote, I am struck by the reflective perspectives and interpretations that SR described from the perspective of a 21 year old college student regarding a teacher and classroom when he was 14 years old. I know Mr. B. very well and indeed he still talks about his former students with respect and encourages them when possible in their endeavors even after many years have elapsed. As a parent, former high school teacher, and current university teacher, I can think of no better example of how caring can and does positively impact students both during schooling and just as importantly during the years that follow graduation. I am quite sure that SR's current memories of Mr. B. have become transformed and enriched in light of later reflection and experience as I write this in the year 2020.

Regarding high school, it is unfortunate that SR's memories first took him back to experiences of noncaring in relation to his English teacher as he described in his letter-

I would not have the inspiration to practice writing with much diligence if not for my high school English teacher Mrs. Danforth (pseudonym). Not because of her guidance or support, but because she was wrong in her assessment of my writing. And, I chose to prove her wrong. She told students what not to write more often than she offered alternatives or solutions and left students stuck using their own judgment with little or no guidance. In hindsight, this has ultimately proven to be a valuable lesson. Now, I use her negative approach to build a strong foundation around "okay, I am a good writer, and here's why." As time elapsed, I realized her teaching style gave me two choices: to become a product of my classroom environment and negatively reinforce myself or decide for myself what to let shape me. The choice did not come easily. There was a time where I was sent into a deeply self-critical place - a place that was doubtful, dark, and resentful. There was even a time I nearly lost my passion for writing and learning itself. This experience also spilled over into other classes and put a tremendous weight on my feelings toward learning even beyond English class. That was a big factor.

Of course, there are usually two sides to a story and more than likely Mrs. Danforth would have a different perspective on this situation. However, there is no question that from SR's perspective, he views this memory as unpleasant yet reflects that he has transformed it in a way that he now uses it as additional motivation to learn - an instance of a metamemory.

Acting as a counter-weight to this previous negative memory, SR also recalled positive instances of caring in the person of his high school math teacher who took the time to explain concepts to him during lunch time and after school. I also recall these instances of caring by this teacher although not as poignantly as SR. In addition, the impact of a high school English teacher (Mr. Zaf) during his senior year continues to this day even after SR's recent graduation from college ---

Mr. Zaf was a legendary English teacher at my high school. His tenure was over 30 years, making his teaching career span in some cases from former students all the way to the son or daughter of these students! He had a reputation for empowerment and challenging learning. Mr. Zaf had a stellar way of making students feel that their writing had value and was worthy of praise. He made students feel capable. He didn't just correct papers, he would workshop sentences with you to develop the most meaning from them. I'll never forget what he signed on the back of my Senior Retrospective... "you have the heart of a poet and the mind of a philosopher." The most important thing that Mr. Zaf used in conjunction with his support and work-shopping was assigning material that "challenged a student's superior intellect," as he'd say teasingly, but you knew he seriously considered all students capable of performing at such a level. We read a fair amount of Shakespeare as well as Beowulf. He relentlessly challenged the class to read more complex works. He 
also gave a vocabulary test every other day and graded on definition which grew in complexity over the course. The way in which he celebrated the most complex of his reading assignments made us want to write at a higher caliber, and most of us successfully did.

It is difficult not to smile when I read this account especially in light of SR's earlier experiences with Mrs. Danforth. While SR describes how he has transformed his interpretation of his negative memories of Mrs. Danforth, I believe that he has also transformed his memories of Mr. Zaf by now contextualizing these memories in light of his experiences and growing maturity.

Regarding college experiences, because SR attended a university that was distant from home, our family interview was also the first time we heard much about his college experiences. SR spoke about his willingness to work hard in classes that were not necessarily his favorite because he perceived his professors as really caring both about him and subject matter. This, of course, struck a warm chord with me since I too am a college professor! It has been found that students who have experienced a caring relationship with professors exhibit a higher level of engagement in learning and a better academic self-concept [30], [16]. I was especially gratified to learn that $\mathrm{SR}$ recognized that neither learning nor caring is confined to the classroom by describing an experience with a Café owner near to his campus. Here is what he wrote when he was a college senior --

I notice now that in most of my college classes, I'm the most talkative student. I find something to contribute to almost every discussion. I believe that $95 \%$ of students in any given classroom, including college, know the material well enough to participate. However, in a class of 30 students, an average of $5-7$ students consistently participate. Why? They may feel that transitioning from listening to speaking is uncomfortable and sets them apart from the rest of the students. Or, they may have been conditioned at a young age to be quiet during class. The amazing thing about Mr. B's and Mr. Zaf classes [middle school and high school respectively] was that all material was an invitation for the class to actively engage in. This definitely reshaped the way it feels to speak in class for me. Now, in the Fall semester of my senior year of college, I actually have to hold myself back from answering questions in a particular class to give other students the chance to join the discussion! I think when it comes to developing strong students, it comes down to a healthy balance of challenging students and supporting them; presenting them with hard work, and letting them know they are up to the challenge. Importantly, within that challenge comes guidance and responsibility; making your standards clear, working with students for them to understand what is expected of them, and putting the rest in their hands to work on for themselves. Because teachers along the way like Mr. B. and Mr. Zaf have shown me these lessons in a way that has stuck with me long-term, I am aware and mindful of how to perform up to my full potential and am very motivated to do so!

SR's connecting his self-reflections of his classroom college experience to his memories of $\mathrm{Mr}$. B. in middle school and Mr. Zaf in high school illustrate another dimension of metamemories and that is the integration of these memories into a continuing self-dialogue as a way to continue to construct our ongoing efforts to construct cohesive world views as well as our identities. Although Erikson [6] saw identity formation as the major challenge of adolescence, it may well be the case that identity development is a lifelong adventure in relation to both our ongoing experiences and our metamemories.

Since both my wife (MR) and I were privy to our son's experiences and perceptions, as caring parents, it was sometimes difficult to listen to his re-storying of painful memories. In regard to Mrs. Danforth [high school English teacher], MR wrote --

In a landmark meeting with Mrs. Danforth, I was astounded to hear her tell us that his work was "sub par." This is when he was in 11th grade and writing had been to that point a strong suit for him. Could this teacher have turned this conference into a learning moment, describing what she was expecting and what was lacking in Patrick's work? Did she offer examples of what was expected? I was so angry and hurt for my son. Not only was he beaten-down from this teacher, he subsequently had to forfeit a lead role in the spring musical which was devastating to him, so deeply embarrassing for a student of 16 years old.

MR then went on to say that because of teachers like Mr. B. and Mr. Zaf, SR was able to lift himself up and become a better writer because of this experience. MR then concluded that "in retrospect, SR learned a great lesson from the Mrs. Danforth situation, and at the same time discovered what caring teaching is all about because SR had enough strong mentor roles to learn from that and I now believe he could be a wonderful teacher in his own right!" Here we have an instance where the memory of another person (MR) has now been transformed because of a shared re-construction and reinterpretation of this memory with SR. As loving parents, we realized that we had to be especially sensitive to allowing our own perceptions and interpretations of our memories to be transformed in a way that always casts SR in a positive light while 
vilifying those whom he has described in a negative light. - the old "bias" taboo! However, my own take on bias is similar to Lichtman [8]: Bias and qualitative research is a topic that challenges both students and their professors. One view is that bias can be eliminated, or at least controlled, by careful work, triangulation, and multiple sources. I do not believe this is true. Bias is a concept that is related to foundationalist, traditional, or postpositivist thinking.

Lichtman [19] goes on to point out that all researchers have particular views on a topic or why would they do them? For this current study, while we recognize our "bias" that SR is a great kid with a great future in front of him, we also recognize that the "halo effect" is still alive and well in all of us for those whom we care about. This is one of those wonderful "challenges" that we must embrace as researchers since we tend to study those things that we are most passionate about.

\section{Findings and Conceptual Underpinnings}

Following the completion of this study, it seemed appropriate to do a follow-up investigation regarding the extent to which the concepts thought to underlie this study were actually based on Piagetian theory, it is quite apparent that SR retrospectively reflected on his experiences and used both assimilation and accommodation in order to continue to strive for equilibrium in relation to his memories of his schooling years. For example, regarding his negative experiences with his English teacher Mrs. Danforth, as noted above:

Now, I use her negative approach to build a strong foundation around "okay, I am a good writer, and here's why." As time elapsed, I realized her teaching style gave me two choices: to become a product of my classroom environment and negatively reinforce myself, or decide for myself what to let shape me.

Here we see how his memory of a negative experience was transformed via accommodation, although with some degree of mental anguish, into a new insight that supported equilibrium. I found that Constructivist Learning Theory resonates throughout the findings. For example, regarding SR's memory of his senior year of college he said --"I notice now that in most of my college classes, I'm the most talkative student. I find something to contribute to almost every discussion." He attributed this to his positive experiences in middle school and high school with Mr. B. and Mr. Zaf "where all material was an invitation for the class to actively engage in. His re-shaping of this memory is consistent with both the individual and social strands of constructivism where learning is continuously re- shaped by individuals so that learning becomes "customized" by and for each of us.

Polanyi's illumination of how propositional and tacit knowledge pervade our ways of knowing was manifested in both SR's narrative especially when there was an obvious interplay of his thoughts and emotions as he sought equilibrium (Piaget) as well as when he incorporated new learning (constructivism). For example, my wife and I were quite aware of the detrimental emotional impacts on him as a consequence of negative experiences with his high school English teacher (Mrs. Danforth). However, here is what he said about this --

I would not have the inspiration to practice writing with much diligence if not for my high school English teacher Mrs. Danforth (pseudonym). Not because of her guidance or support, but because she was wrong in her assessment of my writing. And, I chose to prove her wrong.

What I have discerned from this response is that as SR reflected about this experience, he was thoughtful about a very negative and emotional experience; that is, he transformed these feelings into a manifesto that he could now articulate in clear terms. I am quite sure that these kinds of transformations are pivotal in relation to metamemories.

Finally, when I recently encountered ongoing work related to the role of nostalgia in our lives, I immediately recognized that throughout our interviews, feelings of empathy and ubunto pervaded much of what SR related. For example, as SR this about his middle school teacher (Mr. B.) -- "he was the first teacher to communicate with upperelementary students beyond the syllabus and into our lives", the feelings of ubunto were palpable as he spoke and as my wife and I listened. While nostalgia is often seen as simply sentimentality perhaps to sell products or even as muddle headed thinking, based on a growing acceptance of the powerful role of metamemories in our lives and the current work being done on it, I have a new appreciation of it.

\section{Conclusions and Final Thoughts}

Asking one of my doctoral students (Jane) to review a draft of this article, she wrote in part: "I found I was fascinated by each letter and looked forward to reading the next. It was amazing how much the participant grew with each encounter especially the caring ones."

In line with this observation, it is my belief that interviews not only serve to communicate "what was" but also "what is becoming" as participants and interviewer co-construct new insights and meanings from past events. "Letters to self" also seem to serve 
this dual role of both was and becoming since they not only serve as data collection instruments but also due to the very act of writing engender both reflections and new insights. As I reflect now on both my original memories of SR's elementary school (2002- 2010) and high school (2010-2014) and those regarding college (2014-2018) I find myself putting these memories within a new perspective based on what we shared as a family during the 2016 interview as well as in our follow-up letters and conversations. I seem to have constructed a more integrated perspective of how both positive and negative instances of caring can be used by individuals to re-cast their memories if they so choose in either positive or negative ways. For example, SR when describing Mrs. Danforth (the English teacher he had in high school) whom he characterized as quite uncaring and non-supportive seemed to transform his interpretation of his memories in a way that has resulted in a more positive mindset. Today, I feel a sense of accomplishment rehashing and reflecting upon my time as a debased student. No resentment has brewed in the years since. Think back to times you may have been at arms with a teacher who you felt was against you. Do you feel any resentment? Do you use resentment as a propeller or the accomplishment of producing quality work? Let the desire of work well done be your driver, not the residual contempt from a negative experience drive your goals.

Like SR, I have come to see negative memories as those that can ultimately be re-cast in a positive way. It is also sometimes the case (though not as often) that I have found myself re-casting positive memories into more subdued hues as a consequence of placing these memories into a larger context based on time and experience. For example, while I idolized an uncle of mine because of the way that he treated me (including surprise gifts), I have since learned that he was a carouser and womanizer which I now know caused my aunt a great deal of sorrow. While I will always carry wonderful "flashbulb memories" of my uncle, these memories are now framed within a larger understanding of the social context. I have termed this phenomenon of re-casting or re-framing memories metamemories because it involves not only thinking back to original memories but also transforming these memories based on reflections and experiences that occur following the original events into a revised perceptual framework. Pivotal events for my own metamemory transformation for this study were the family interview and SR's letter that enabled me to "see" recalled events through both an historical as well as a dynamic temporal lens as experienced by SR. Because each of us are not only self-learners but also social-learners, I found my own memories being transformed as SR shared his own transformed memories during both the initial interview as well as through his letter-to-self. There seems to be an inherent resilience, creativity, and drive in us that enable us to reshape and transform memories in a way that supports the ongoing re-construction of our own worldviews.

From a self-phenomenological perspective, I find myself actively trying to discern how I have experienced this foray into family research as it relates to schooling. A close reading of the SR and MR letters has led me to appreciate how research on families can shed light on some intractable issues in the field of education. Although most families will not engage in formal research, if we recognize that interviews are nothing more than focused conversations, perhaps we can learn as families to "interview" each other in a caring way and on a regular basis to learn what is on our hearts and minds and thereby be able to offer loving support when it is most needed. Perhaps we might even re-invigorate the lost art of letter writing to both self and others as a way to further promote understanding. However, it might also be the case that it is only the medium of time and perspective that enable us to transform our memories of positive and negative experiences and recast them into metamemories. I think that the family interview and our letters provided such an opportunity for the three of us to do just that.

Wolcott [32] speaking about the respective roles of description, analysis, and interpretation in qualitative data analysis states that thoughts related to data analysis and interpretation may linger for years, just as details of events long forgotten may pop into one's head, or experiences in a new field setting may suddenly prompt a fresh perspective for rethinking the meaning of events in an earlier one. So, when we talk about the transformation of memories related to experiences of caring and noncaring in school or other important aspects of our lives, it is important for us to have others listen and share in transforming memories within the context of a caring environment.

It is also important to note that with qualitative research, there is usually improvisation that accompanies the development and conduct of a study - and that was certainly the case here. For example, when trying to clarify the complex nature of this study in contrast to the first study [2], my son and I had several conversations including a particularly memorable one when I was visiting him at his university and we met on a Sunday morning in November at a café near the campus. From a descriptive standpoint, I wrote much of this article in "real time" while we were seated next to a warm fireplace with flames licking about. It was a cold morning and the fire lent not only physical warmth but also an environment that seemed to make conversation and understanding flow more easily. In addition, a mother with two young children, who seemed to be preparing for an upcoming dance 
lesson, were around the other side of the fireplace and were sharing in the warmth while also providing visual expression to the transferability of caring in education across families and generations. I also have found that I have been "mindfulness" as I collected data [18] where "the core of mindfulness is a heightened awareness that is the result from paying attention on purpose". SR's description of how the negative memories of Mrs. Danforth were transformed into positive ones continues to resonate with both my wife and me and have provided us with a lens to better understand our son - both who he is now as well as how the challenges he faces offer opportunities for further growth. This lens seems to embody Piaget's notion of "assimilation" and "accommodation" in a concrete yet more inclusive way to reveal to SR how he can continue to grow along not only cognitive but also emotional, social, and spiritual paths. It also helps us as parents to hopefully guide his growth with more grace and wisdom.

I found findings related to the the underpinnings of this study (Piagetian Learning Theory, Constructivist Learning Theory, Polanyi's tacit and propositional knowledge, and nostalgia research) to be most revealing. While I am gratified to have been able to appreciate these connections to metamemories, I am quite sure that there are other theories and concepts in the fields of psychology, sociology, and anthropology that would shed even more light on this phenomenon including metacommunication where the original intent of a communication is interpreted differently by different individuals. I am also quite certain that additional connections can be found in in art, music, novels, and theater. In fact, it is probably these latter nonacademic pursuits where our emotions become more integrated with our reasoning and therefore help us to recognize, accept, and appreciate more fully that we humans are also "integrated" - it is both our thinking and feeling that contribute to our memories as well as how we come to transform them into metamemories.

Qualitative research can indeed be rife with noncontrol and "contamination" of data but at the same time very rich with the potential for helping to understand what really matters in teaching and learning as well as in other important areas of our lives. I recognize that not every family will decide to undertake a formal research study such as this one; however, the real key may be simply cultivating an attitude of adventure, caring, and mindfulness as we revel in the "ordinary" of our daily lives including the importance of our metamemories no matter the specific area or context of the inquiry. It is only through our awareness and cultivation of not only how we perceive experiences but also how we continuously re-construct them into metamemories that we can come to appreciate how wonderfully complex we are and that all inquiry approaches offers us opportunities to learn more about these complexities.

\section{References}

[1] Berliner, D.C., (2002). Educational research: The hardest science of all. Educational Researcher, 31(8), 1820.

[2] Bernauer, J.A., Bernauer, M.P., and Bernauer, P.J., (2017). A family affair: Caring in teaching and implications for teacher and researcher preparation. Brock Education Journal, 26(2), 4 - 15.

[3] Creamer, E.G., (2018). An introduction to fully integrated mixed methods research. Sage.

[4] Creswell, J.W. and Plano Clark, V.L., (2011). Designing and conducting mixed methods research (2nd ed.). Sage.

[5] Creswell, J. W. and Poth, C.N., (2018). Qualitative inquiry and research design: Choosing among five approaches (4th ed.). Sage.

[6] Erikson, E. H., (1963). Childhood and Society (2nd ed.). New York, NY: Norton.

[7] Gage, N. L., (1989). The paradigm wars and their aftermath: A "historical" sketch of research on teaching since 1989. Educational Researcher, 18(7), 4-10.

[8] Guba, E. G., (1967). The expanding concept of research. Theory into Practice, 6(2), 57-65.

[9] Guba, E. G., (1981). Criteria for assessing the trustworthiness of naturalistic inquiries. Educational Communication and Technology Journal, 29(2), 75-91.

[10] Guba, E. G., (1990). The paradigm dialog. Sage Publications.

[11] Heider, K. G., (1975). What do people do? Dani autoethnography. Journal of Anthropological Research, 31, 317.

[12] Hesse-Biber, S. N., (2010). Mixed methods research: Merging theory with practice. The Guilford Press.

[13] Jaeger, R. M., (1988). Complementary methods for research in education. American Educational Research Association.

[14] Kelly, G. A., (1963). A theory of personality: The psychology of personal constructs. New York, NY: W.W. Norton and Company.

[15] Kessous, A. and Roux, E., (2008). Nostalgia as connection to the past: A semiotic analysis. Qualitative Market Research, 11(2), 192-212.

[16] Komarraju, M., S. Musulkin., and G. Bhattacharya, (2010). Role of student-faculty interactions in developing college students' academic self-concept, motivation, and 
achievement. Journal of College Student Development, 51(3), 332-342.

[17] Kuhn, (1970). The structure of scientific revolutions (2nd ed.). The University of Chicago Press.

[18] Lemon, L., (2017). Applying a Mindfulness Practice to Qualitative Data Collection. The Qualitative Report, 22(12), 3305-3313. http://nsuworks.nova.edu/tqr/vol22/iss 12/ 14 (Access Date: 14 December, 2020).

[19] Lichtman, M., (2013). Qualitative research in education: A user's guide (3rd ed.). Los Angeles, CA: Sage.

[20] Lincoln, Y. S. and Guba, E. G., (2013). The constructivist credo. Walnut Creek, CA: Left Coast Press, Inc.

[21] Muller, J., (2015). Exploring 'nostalgia' and 'imagination' for ubunto-research: A postfoundational perspective. Verbum et Ecclesia 36(2), Art. \#1432, 1-6.

[22] Muncey, T., (2010). Creating autoethnographies. Los Angeles, CA: Sage.

[23] Nisson, J., (2021). Nostalgia is good for you. The Saturday Evening Post, January/February, pp. 10-12.

[24] Dwyer, L.M, and Bernauer, J.A., (2014). Quantitative research for the qualitative researcher. Sage.

[25] Piaget, J. (1954). The construction of reality in the child. (M. Cook, Trans.). New York, NY: Basic Books.

[26] Piaget, J., (1963). Origins of intelligence in children. New York, NY: Norton.

[27] Polanyi, M., (1962). Personal knowledge. Chicago, IL: The University of Chicago Press.

[28] Polanyi, M., (1966). The tacit dimension. Chicago, IL: The University of Chicago Press.

[29] Tierney, W. G., (1998). Life history's history: Subjects foretold. Qualitative Inquiry, 4, 49-70.

[30] Umbach, P., and M. Wawrzynski, (2005). Faculty do matter: The role of college faculty in student learning and engagement. Research in Higher Education 46(2), 153184.

[31] Vygotsky, L. S., (1987). The genetic roots of thinking and speech. In R.W. Rieber and A.S. Carton (Eds.), Problems of general psychology, Vol. 1. Collected works (pp. 101-120). New York, NY: Plenum. (Work originally published 1934).

[32] Wolcott, H. F., (1994). Transforming qualitative data: Description, analysis, and interpretation. Thousand Oaks, CA: SagePublications.

[33] Wolcott, H. F., (2008). Ethnography: A way of seeing. Altamira Press.
[34] Woolfolk, A. H., (2014). Educational psychology. (12th ed.). Boston, MA: Pearson. 